Article

\title{
Effect of Sowing Dates on Fatty Acids and Phytosterols Patterns of Carthamus tinctorius L.
}

\author{
Jane Roche ${ }^{1,2}\left(\right.$, Zephirin Mouloungui $^{1}\left(\mathbb{D}\right.$, Muriel Cerny $^{1}$ and Othmane Merah ${ }^{1,3, *} \mathbb{C}$ \\ 1 Laboratoire de Chimie Agroindustrielle, LCA, Université de Toulouse, INRA, 31030 Toulouse, France \\ 2 Laboratory of Genetics, Diversity and Ecophysiology of Cereals UMR INRA/UCA 1095, University of \\ Clermont Auvergne, 63006 Aubière, France \\ 3 Université Paul Sabatier, IUT A, Département Génie Biologique, 32000 Auch, France \\ * Correspondence: othmane.merah@ensiacet.fr; Tel.: +33-534-323-523
}

Received: 7 June 2019; Accepted: 11 July 2019; Published: 16 July 2019

\begin{abstract}
Field experiments were carried out at the Regional Centre of Experimentation in Organic agriculture at Auch (near Toulouse, South west of France). Due to the high potential applications for its oil components such as fatty acids and phytosterols, safflower (Carthamus tinctorius L.) is considered as an emerging crop. Safflower plants, as many other oil crops, are submitted to environmental stresses that modify seed composition. Nevertheless, few reports are available about the effects of environmental conditions on fatty acid and phytosterol compositions in safflower. Different rainfall supplies can be managed by delaying the sowing dates. In this study, fatty acid and phytosterol contents have been evaluated in safflower seeds cultivated at two sowing dates (conventional and late) that led to a differential of rainfall during seed development. At harvest, seeds were used for oil extraction. Fatty acid composition was performed by using GC-FID. A set of seeds was dehulled to separate the almond (embryo) and hull to release the extraction and measurement of sterol contents in the two compartments by GC-FID. A delay of sowing increased the content of all sterol categories but induced a significant decrease in fatty acids. The ratio of saturated to unsaturated fatty acids increased under a delaying sowing. The repartition of phytosterols was $\frac{3}{4}$ and $\frac{1}{4}$ of total sterols in the embryo and the hull, respectively. These results could make the use of hull (considered as waste) possible, help breeders to improve safflower oil composition and develop new industrial applications.
\end{abstract}

Keywords: safflower (Carthamus tinctorius L.); delay of sowing; sterols distribution; lipids accumulation; hull; seed

\section{Introduction}

Lipids, which are important components in the human diet, can be provided by plant oilseeds cultivated worldwide. They contain a high concentration of unsaturated fatty acids known to prevent cardiovascular diseases [1]. Oils contain also minor lipids like phytosterols that prevent the free radicals' damages by lowering the cholesterol level in human blood. Two to three grams of phytosterols are sufficient to reduce the LDL cholesterol fraction [2]. Their cellular antioxidant activity is related to their capacity to transform allylic free radical to more stable free radicals, particularly under frying conditions [3]. Considered as active food ingredients, phytosterols are used in diverse commercial food products, such as milk, cheese, spreads or chocolate products. Due to their high added value, chemically modified phytosterols are also used for non-food purposes as raw materials in the production of pharmaceuticals and cosmetics [4]. Mainly cultivated in Asia, North and South America, safflower (Carthamus tinctorius L.) has several known industrial applications such as food, cosmetics, pharmaceuticals and feed industries. Safflower represents a very interesting crop to give an alternative option for countries that cannot afford to consume olive or other functional oils [5] and to 
develop non-food industrial applications, due to the presence of functional components (saturated and unsaturated fatty acids and phytosterols). However, the seed yield and oil remains low due to the poor management techniques [6]. Moreover, it is well known that environmental conditions affect oil content and fatty acid composition of safflower and other oilseed crops [7,8]. A better understanding of the effects of management techniques on fatty acid and phytosterol contents and compositions content is important to further improve oil quality under the restricting environmental conditions. Only few studies aimed at studying the effects of environmental conditions on the unsaponifiable oil composition in oil crops $[9,10]$.

Here, the effect of the delay of sowing (conventional and late) in fatty acids and phytosterols composition was evaluated. It could help breeders and producers to understand the influence of environmental conditions on the composition of safflower oil. In addition, the phytosterol contents in the hull and in the embryo were measured to understand their distribution in the seed that also could give information to the breeders to investigate seeds with modified proportions for specific applications.

\section{Materials and Methods}

\subsection{Plant Material, Trial and Environmental Conditions}

Seed oil, fatty acids and sterol contents were studied on one genotype (Arizona) usually used in organic agriculture.

The experiment was conducted in 2007, in south-western France at the Regional Centre for experimentation under Organic Agriculture, at Auch (32). Field trial was done on a deep limestone clay silt soil with high water-holding capacity. Two sowing dates were used to generate temperature and rainfall variations during seed development. The trial was sown at a density of 300 seeds by $\mathrm{m}^{2}$ on April 15th, for the conventional sowing date (CS); and on June 2nd, for the late sowing date (LS) which was chosen to reach most contrasted conditions between the two sowing dates considering the best combination between the climate (based on the average of 55 years analysis) and farmers practices (sowing date) that is usually done in the South of France for this species. The development of the crop was monitored weekly. A complete randomised block design was used in this experiment with two treatments (two sowing dates) and three replications. Seeds were harvested at beginning (5th September) and mid-September (16th September) for the conventional and late sowing date, respectively. Seeds were harvested at maturity when the water content of $20 \%$ was reached.

At harvest, a set of seeds was dehulled manually in order to separate almond (embryo) and hull to perform the extraction and measurement of sterol in the each compartment.

\subsection{Fatty Acids and Sterol Contents Determination}

The determination of fatty acid (FA) composition was performed according the solubility of oil in TerButylMethyl Ether (ME0552, Scharlab, Barcelona, Spain) based on the method (Norm ISO 5509,1990 ), which allows the transformation of FAs to methyl esters. Seed samples ( $3 \mathrm{~g}$ of each one separately) were ground in $5 \mathrm{~mL}$ of TerButylMethyl Ether and then filtered across a GPH filter of $13 \mathrm{~mm}$-diameter. Based on the norm NF EN ISO 12966-3, $100 \mathrm{~mL}$ of the filtrate were mixed with $50 \mathrm{~mL}$ (at 0.2 M) TriMethylSulphonium Hydroxide in methanol (Macherey Nagel, Hoerdt, France). This allowed obtaining a mix from which $1 \mathrm{~mL}$ was injected into GC-3800 chromatograph (Varian 3900, Palo Alto, Milpitas, CA, USA) associated to a Flame Ionization Detector (FID) and equipped with a CP Select CB $50 \mathrm{~m}$ capillary column (D: $0.25 \mathrm{~mm}$ ). Oven temperature was initially held at $185^{\circ} \mathrm{C}$ for $40 \mathrm{~min}$. This temperature increased by $15^{\circ} \mathrm{C} \mathrm{min}-1$ to reach $250{ }^{\circ} \mathrm{C}$ and then maintained there for $10 \mathrm{~min}$. The temperatures of the injector and detector were fixed at $250^{\circ} \mathrm{C}$. A known standard mixture of Fatty Acid Methyl Ester (FAME) of rapeseed oil (Supelco, Bellefonte, PA, USA) was used as an external standard and served to estimate the FAME of the samples by comparison of the retention times.

The small-scale sample extraction method [10] was used to extract and determine the sterol content of safflower. Ground seed samples $(1.3 \mathrm{~g})$ were added to each tube containing $100 \mu \mathrm{g}$ of 
cholestanol (dihydrocholesterol; Aldrich Chemicals Co., Saint-Quentin-Fallavier, France), used as an internal standard. The extraction method used to extract and determine the sterol content of safflower was based on those developed by Roche et al. [10]. One hundred micrograms of cholestenol (Aldrich Chemicals Co., 38070 Saint-Quentin-Fallavier, France, internal standard) were added to each sample $(1.3 \mathrm{~g})$ of ground seeds of safflower. Ethanolic $\mathrm{KOH}(1 \mathrm{M})$ (TITRINORM, Prolabo) for $60 \mathrm{~min}$ at $75^{\circ} \mathrm{C}$, were then added in order to perform saponification. Distilled water $(1 \mathrm{~mL})$ was added to each sample and the extraction of unsaponifiable fraction was extracted from the saponified lipids by adding $6 \mathrm{~mL}$ of iso- hexane (Merck, Lyon, France). The silylation of sterols was released by a mixture of $\mathrm{N}$-methyl-N-trimethylsilyl-heptafluorobutyramide (MSHFBA; Macherey-Nagel, Hoerdt, France) and 1-methylimidazole (Sigma, Saint-Quentin-Fallavier, France). The sterol trimethylsilyl ether derivatives $(1 \mathrm{~mL})$ were injected into a Perkin-Elmer GC equipped with a CP-SIL 5CB $30 \mathrm{~m}$ column (i.d.: $0.25 \mathrm{~mm}$ ), and an on-column injector. Detection was done with FID.

\subsection{Statistical Data Analysis}

Statistical analyses were carried out on all the plots with three analytical replications using a statistical package (Sigmastat Version 2.0, USA). Analyses of variance and Duncan test were used to determine the significance between sowing dates.

\section{Results}

\subsection{Characterization of Environmental Conditions}

Figure 1 presents rainfall and temperatures during the two plant cycles, corresponding to the conventional and late sowing dates, and were compared to the weather data of the last 55 years. The rainfall amount was lower than the half century precipitations $(-171 \mathrm{~mm})$ observed for the same period in the same area in 2007. Similarly, whatever the sowing date, the rainfall was lower than the half century precipitations. In contrast, temperatures were quite similar in 2007 and the average of 55 years. The effects of the rainfall were managed by the delay of sowing. Indeed, plants sowed at conventional date received twice the rainfall than those of the late sowing date. The mean temperature at the late sowing date was $1{ }^{\circ} \mathrm{C}$ higher than at the conventional date (Figure 1).

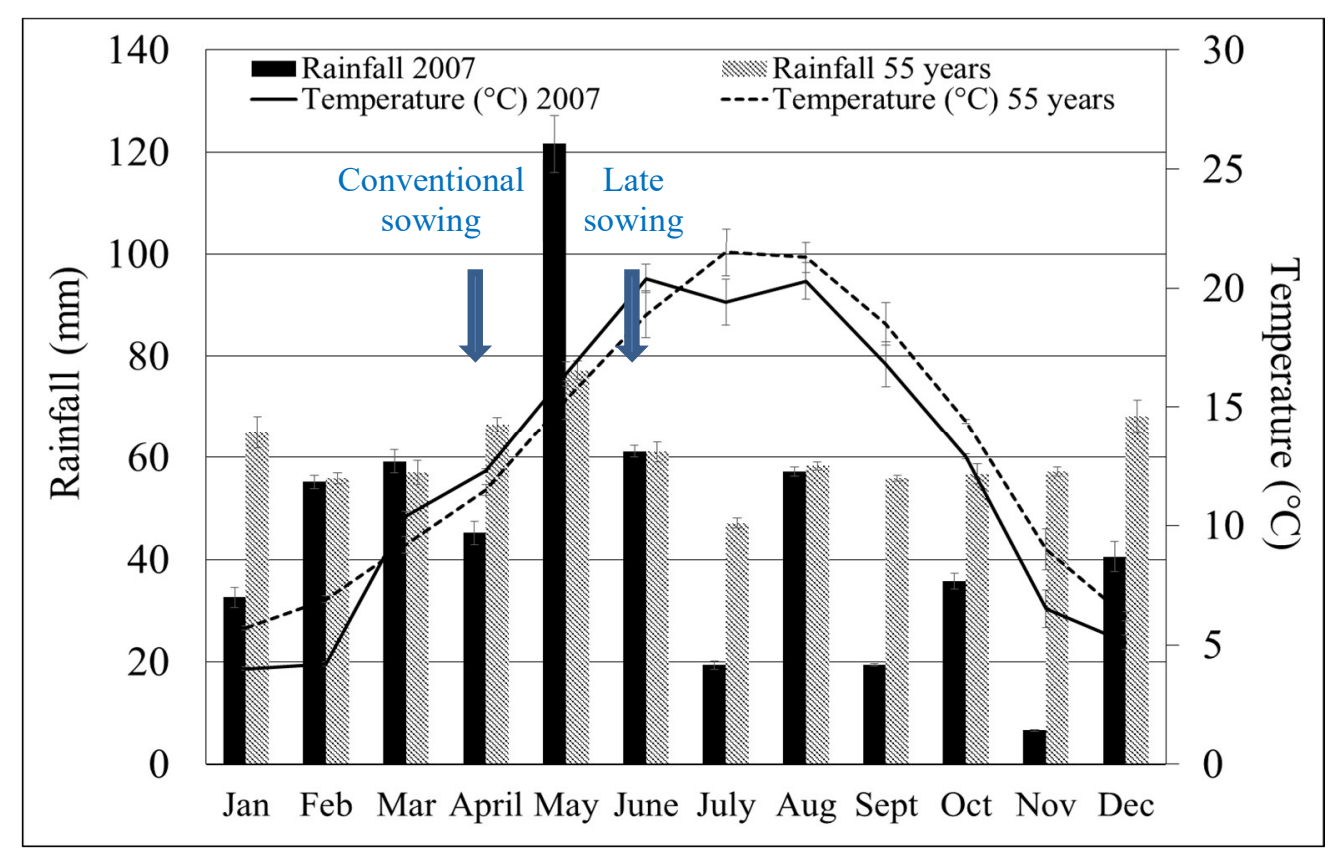

Figure 1. Mean monthly temperatures and rainfall during the cropping season of 2007 and average of 55 years in Auch (South West of France). 
The delay of sowing is an easy implemented cultural practice that is commonly used by the farmer to get favorable conditions for crops to cue environmental stresses that allow changes in the physiological processes and lead to important yield losses. Two sowing dates were chosen to examine the effects of this practice in terms of cultural temperatures and rainfall conditions and to analyse these effects on the accumulation of industrial components of interests (fatty acids and phytosterols) that could be potentially valorised by farmers.

The mean temperature, for the two sowing dates, was around $18{ }^{\circ} \mathrm{C}$ over the whole growing season, whereas the rainfall amount was nearly $37 \%$ less under the late sowing date compared to the conventional one (Table 1).

Table 1. Rainfall (mm) and mean daily temperature $\left({ }^{\circ} \mathrm{C}\right)$ during the growing season of the two trials.

\begin{tabular}{ccccc}
\hline & Sowing Date & Harvest Date & Rainfall (mm) & $\begin{array}{c}\text { Mean } \\
\text { Temperature }\left({ }^{\circ} \mathbf{C}\right)\end{array}$ \\
\hline Conventional sowing & $15 / 4 / 07$ & $5 / 9 / 07$ & 304.6 & 17.8 \\
Late sowing & $2 / 6 / 07$ & $16 / 9 / 07$ & 193.0 & 18.0 \\
\hline
\end{tabular}

\subsection{Phytosterols Distribution in Embryo and Hull Compartments of Safflower Seeds}

The total sterol content in the embryo and in the hull were analysed separately, for seeds harvested in the conventional sowing. More than $26 \%$ of total phytosterols were contained in the hull at harvest (Figure 2). This repartition resulted mainly from the desmethylsterol part with $26.6 \%$ in the hull whereas dimethyl and methylsterol proportions were lower compared to desmethylsterols $19.7 \%$. Similar sterolic profiles were detected for the hull and embryo, except stigmasterol which was nearly 1.5 higher in the hull than in the embryo (Figure 2).

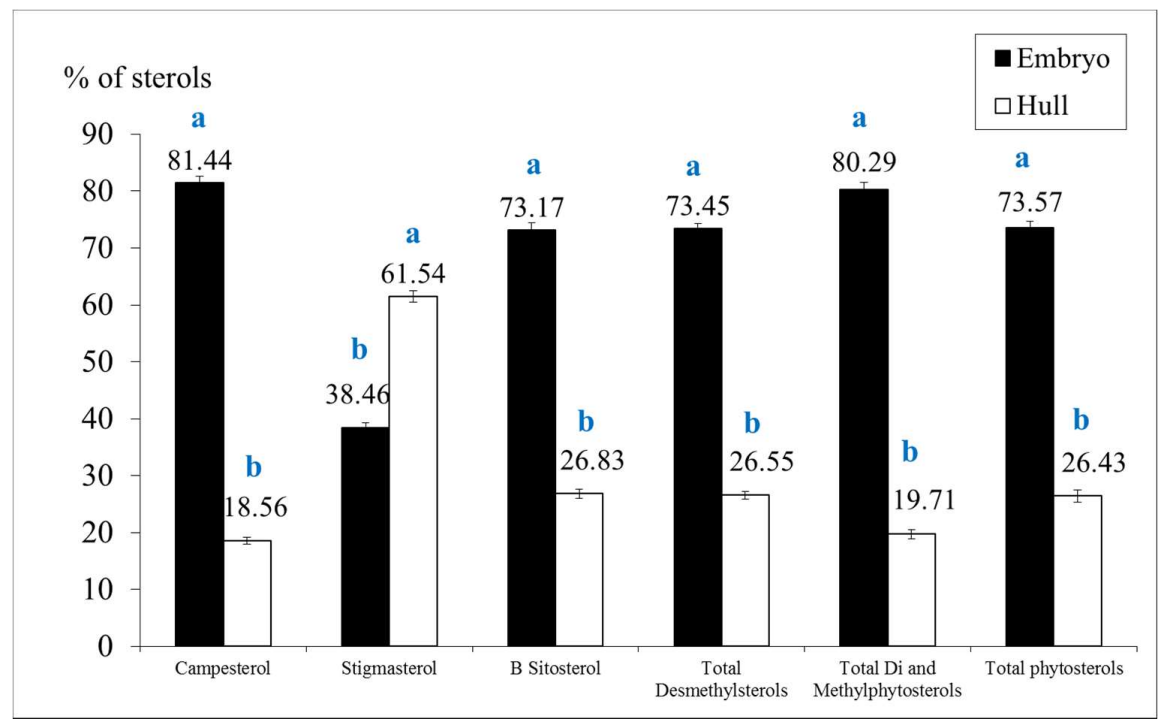

Figure 2. Distribution of phytosterols between the embryo and hull of safflower seeds cultivated under conventional conditions (for each sterol of group means with the same letter are not significantly different).

\subsection{Effect of Two Sowing Dates on Phytosterol and Fatty Acid Accumulation in Safflower Seeds}

Unsaturated fatty acids constituted more than $87 \%$ of the total with oleic and linoleic being the majority fatty acids. Palmitic and stearic acids were the most present saturated ones (Figure 3). As expected, late sowing resulted in significantly lower fatty acid content (Table S1). Unsaturated fatty acids were reduced markedly compared to saturated ones (Figure 3). Consequently, the ratio of SFA/PUFA slightly increased with the delay of sowing. 


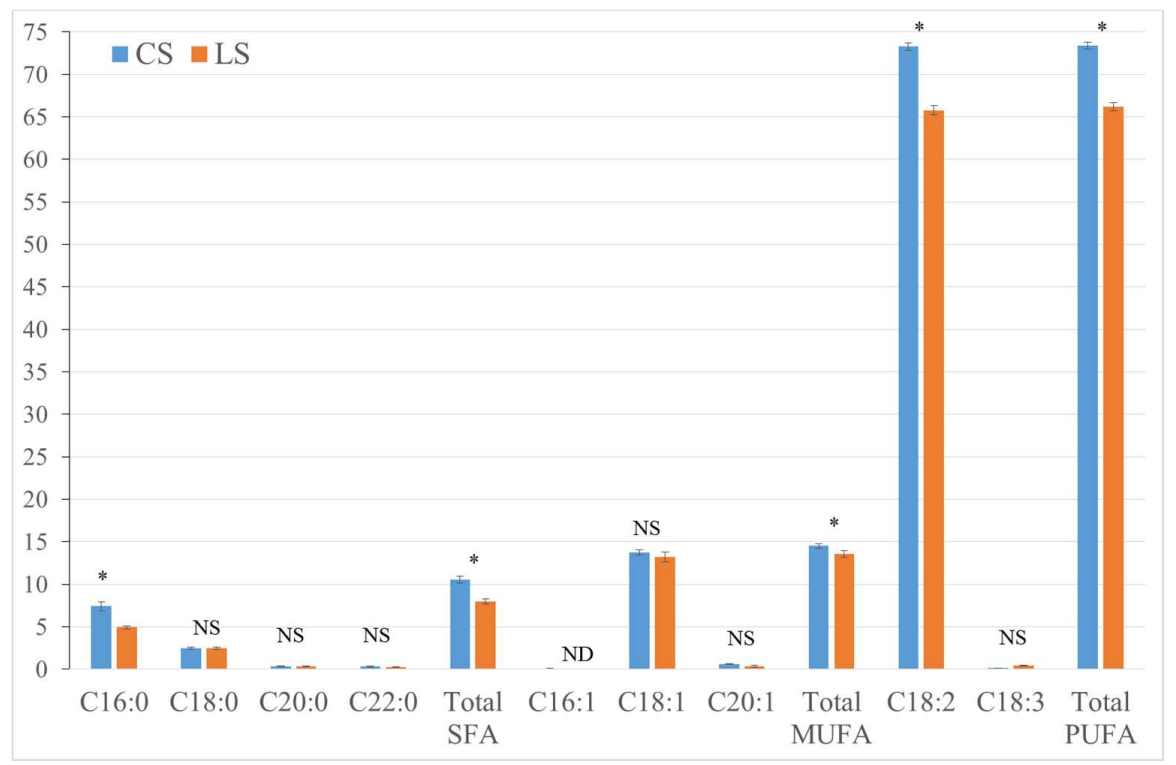

Figure 3. Fatty acid composition of safflower seeds cultivated under conventional (CS) and late sowing dates (LS) in Auch (South West of France) in 2007. The asterisk indicates that means are significantly different. ND: Non-determined. NS: Non-significant.

Safflower whole seeds contain almost $92 \mathrm{mg} / 100 \mathrm{~g}$ of seed dry matter (SDM) of total sterols at maturity in the conventional sowing. Ninety-one percent of them are desmethylsterols represented mainly by $\beta$-sitosterol, campesterol, stigmasterol (Figure 4). The late sowing date had affected significantly total sterols of about $24 \mathrm{mg} / 100 \mathrm{~g}$ of SDM representing around $26 \%$ of the total sterols accumulated in the conventional sowing date. This is a consequence of its impact on desmethylsterols, the main category, which represent $91.4 \%$ and $90.8 \%$ of the total sterol content in the late and the conventional sowing dates. Except for the $\Delta-5$ avenasterol and citrostadienol contents, for which a significant decrease was observed, a delay of sowing increased the content of all sterol categories (Table S2).

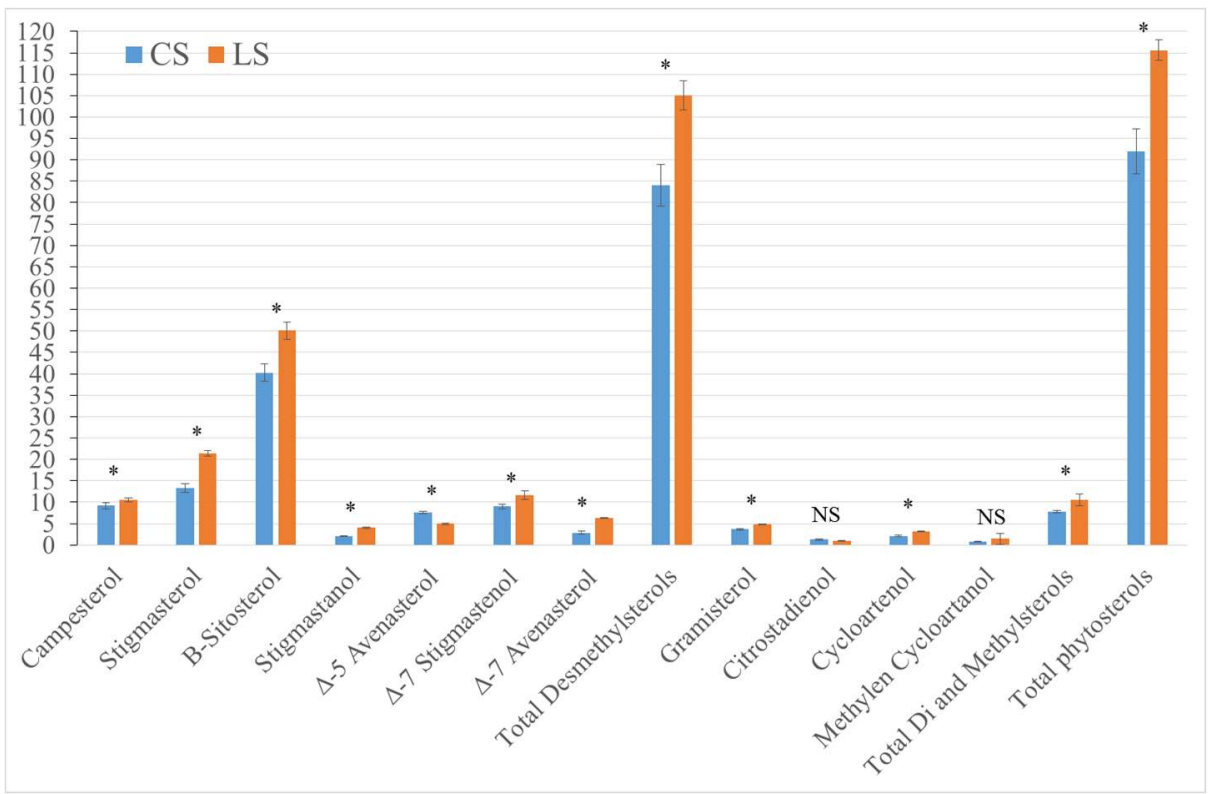

Figure 4. Phytosterol composition of safflower seeds cultivated under conventional and late sowing dates in Auch (South-West of France) in 2007. The asterisk indicates that means are significantly different. NS: Non-significant. 


\section{Discussion}

Adaptations of cultural practices, such as delaying the sowing date, are largely used by farmers to manage environmental conditions to reach optimal yields of oil crops. Particularly, delaying the sowing is used to avoid many diseases [11,12] because weather conditions are modified, i.e., the rain is less abundant and the crop growth cycle could be significantly reduced. In this experiment, the weather conditions recorded during the growing season were characterized by a lower rainfall amount in 2007 ( $30 \%$ less) during grain formation and filling (June to September) compared to the half century data (Figure 1). In addition, a reduction of $37 \%$ of rain under the late sowing compared to the conventional one was observed. Mean temperatures were similar over the growing season. Therefore, experimental conditions could be considered as a moderate water stress which affected lipids production.

\subsection{Effect of Delaying Sowing Date on Fatty Acids Composition in Safflower Seeds}

The fatty acid composition of safflower seeds observed in our study was quite similar to those reported in several studies $[13,14]$. High proportions of polyunsaturated fatty acids and sterols were observed, which confirm the potential interest of safflower oil for medicinal and dietetic purposes [15-19]. Unsaturated fatty acids represented $87.9 \%$ and $79.8 \%$ in the conventional and late sowing dates tested, respectively (Figure 3). Genotypic variation of fatty acid composition in safflower has been reported in a similar range [6,16-18]. Small quantity of Arachidic (C20:0), behenic (C22:0) and ecosenoic (C20:1) acids was noticed (Figure 3) which is in accordance with results already observed in other reports on safflower [6,20-22].

Delaying the sowing date induced a decrease of unsaturated fatty acids in our experiment. Environmental effects (temperature or water regimes) have already been described to impact significantly the seed composition of several oil crops [23-25]. More recently, the effect of intercepted solar radiation was reported. This later study emphasized the importance of environmental conditions in determining oil and sterols quality in sunflower [26]. Nevertheless, these studies were performed around the world and reported differences in fatty acid content on collections of genotypes from several regions with different degrees of adaptation to environmental conditions. Interestingly, the increase of polyunsaturated fatty acids content under conventional sowing date was mainly due to the rise of linoleic acid content (Figure 3). These results are in contrast with those obtained in sunflower. Indeed, a negative correlation has been demonstrated between the two main unsaturated fatty acids (oleic and linoleic acids) under a late sowing date [24]. Those results may suggest specific pathways to accumulate unsaturated fatty acids in safflower when compared to sunflower. Moreover, on both species, it has been demonstrated that delaying sowing dates, which leads to higher temperatures, would be responsible for this negative correlation [14,27]. The absence of correlation observed between oleic and linoleic acids seems more related to the water deficit during the experiment than to the difference in temperature between the two sowing dates (Figure 1 and Table 1). This result may be interesting in order to modify the potential composition of fatty acids for specific industrial purposes.

\subsection{Sterols Content and Repartition in Safflower Seeds}

The distribution of sterols among the seed compartments observed in safflower was quite similar to results reported in other Asteraceae and Brassicaceae $[23,27]$. In coriander, pericarp contributes to $1 / 3$ of the total sterols of whole fruits [28].

Sterols and their saturated form, phytostanols, represent important food constituents, which have a high impact on human health. These compounds are structurally similar to cholesterol and thus have beneficial biological functions when incorporated in diet [29]. The main sterol member in most oil seeds, $\beta$-sitosterol, was found as the dominant sterol during different ripening stages of safflower seeds (Figure 4) which is in agreement with results reported elsewhere [30,31]. Similarly, the genotypic effect on sterol was analysed in a collection of varieties of safflower, $[6,22,32]$ and reported that $\beta$-sitosterol is the dominant phytosterol. 
In sunflower, phytosterols content was found to be dependent on environmental factors [19], genotype and climatic conditions [10,33]. Ben Moumen et al. [6] have highlighted the importance of growing conditions on the phytosterol content determination in safflower.

Different phytosterols and fatty acid profiles and contents were observed when the plants were cultivated under a late sowing date compared to a conventional one (Figures 3 and 4 ). These differences are related to contrasted amounts of rainfall, instead of temperatures, recorded for both sowing dates (Figure 1 and Table 1). Climatic conditions may influence the sterols composition and profile. The $\beta$-sitosterol+stigmaterol/campesterol ratio has been used as an indicator of plant reaction to weather conditions [10]. Indeed, stigmasterol and sitosterol result from the activity of Sterol methyltransferase 2 (SMT-2), which modifies gramisterol into sitosterol after several biochemical transformations (Figure 5). This activity is released instead of the transformation of gramisterol on campesterol instead of $\beta$-sitosterol and stigmasterol. In our study, this ratio was 5.82 and 6.75 in the conventional and late sowing dates, respectively, which was in agreement with Roche et al. [10] in sunflower and Ben Moumen et al. [6] in safflower. Indeed, this balance depends on SMT enzymes involved in sterol biosynthesis (Figure 5). Our results mirrored that the SMT-2 activity may have been probably more important under late sowing conditions than under the conventional date. Lindsey et al. [34] have reported, in Arabidopsis mutants, that overexpressing SMT-2 results in higher accumulation of $\beta$-sitosterol highlighting the involvement of this enzyme in the regulation of sitosterol/campesterol balance. Through the activity of the SMT-2 enzyme, results on safflower indicated that it may be possible to modify the sterol and fatty acid contents and composition by cultural practices management $[25,26]$.

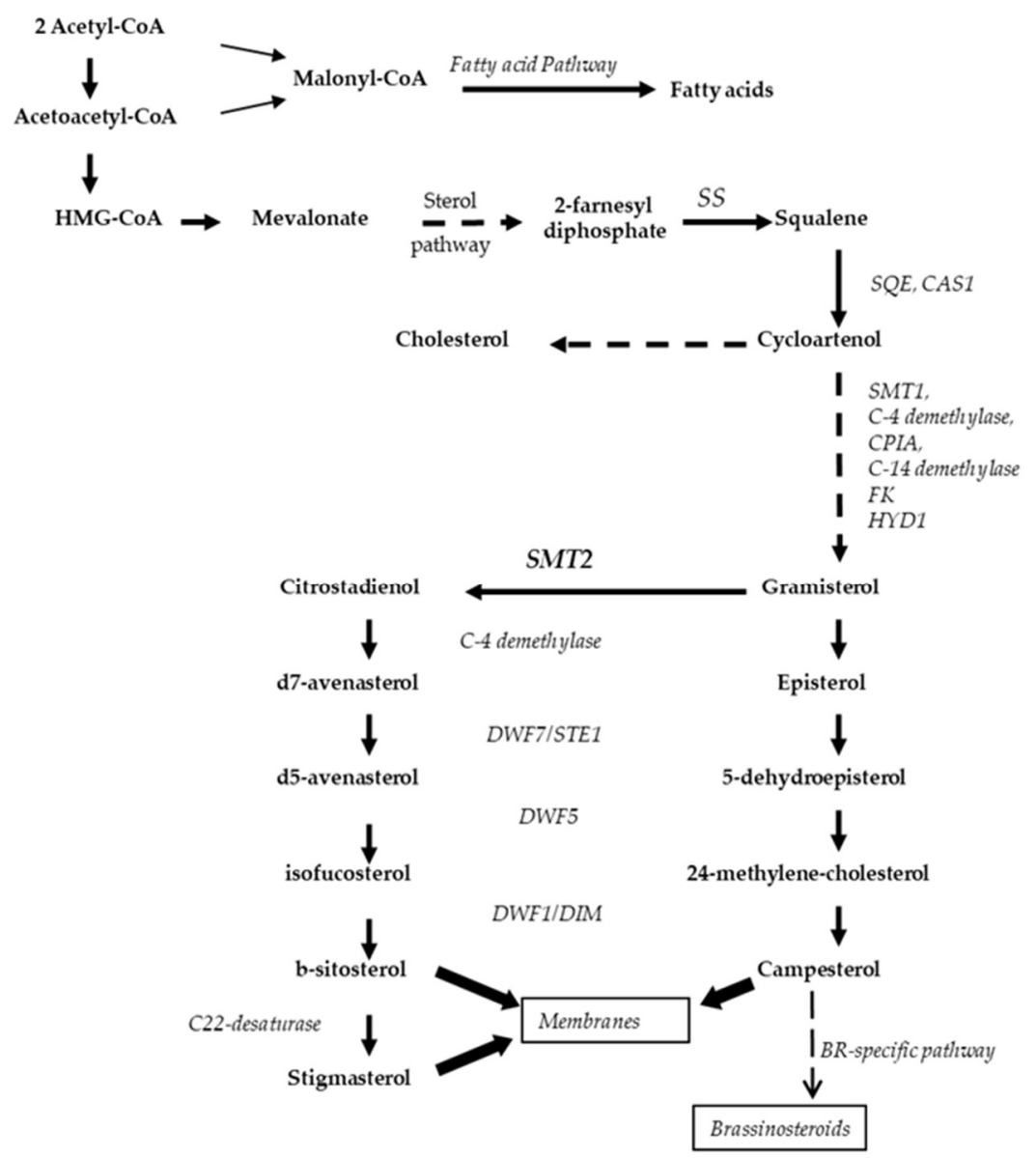

Figure 5. Simplified hypothetical relationships between sterol and fatty acid biosynthesis pathways in Asteraceae. 
CAS1: CycloArtenol Synthase; CPI1: CycloPropyl Isomerase; FK: C14 reductase; HYD1: C8,7 isomerase; DWF7/STE1: $\Delta^{7}$ sterol C5 reductase; DWF5: $\Delta^{7}$ sterol C-7 reductase; DWF1/DIM: C24 reductase; SMT1: Sterol-Methyl Transferase 1, SMT2: Sterol-Methyl Transferase 2, SS: Squalene synthetase; SQE: Squalene Epoxidase.

In terms of the distribution of phytosterols in the seed, the stigmaterol was the only sterol that presented a higher concentration in the hull compared to the embryo. As described in sunflower seeds [27], this result suggested that this sterol may have a different function in the protection of the seed structures.

The late sowing date affected positively the sterol content and negatively the fatty acid composition (Figures 3 and 4). The impact observed on sterols and fatty acid composition could be explained by the fact that cytoplasmic acetyl-CoA required in the synthesis of both fatty acid and phytosterols did not fit all the carbon demands. Similar trends have already been reported in sunflower $[26,33]$ and rapeseed [35] studies. Indeed, the QTL of erucic acid and sterols colocalizations resulted from the pleiotropic effect exerted by the erucic acid genes in rapeseed $[35,36]$ and a negative correlation was found between sterols and oil content in sunflower [24,26]; which suggests that the carbon allocation may be in favour of phytosterols.

\section{Conclusions}

Results reported in this study highlighted the effect of the sowing date on the fatty acid composition and phytosterols profile and content in safflower seeds. Large amounts of polyunsaturated fatty acids and sterols were found in safflower seeds confirming therefore the potential interest of safflower oil for medicinal and dietetic interests. Late sowing may increase the sterol composition and content. At the same time, a decrease in unsaturated fatty acids was observed. Moreover, it was observed that $26 \%$ of sterols of the seed were located in the hull. These findings underlined the possibility of increasing the sterol content by managing the date of sowing of safflower. The ability to shell the safflower seed, as it has been done for other Asteraceae species, and to extract sterols for a high value-added exploitation.

Supplementary Materials: The following are available online at http://www.mdpi.com/2076-3417/9/14/2839/s1, Table S1: Fatty acid composition of safflower seeds cultivated under conventional and late sowing dates in Auch (South West of France) in 2007, Table S2: Phytosterol composition of safflower seeds cultivated under conventional and late sowing dates in Auch (South-West of France) in 2007.

Author Contributions: J.R. and O.M. developed the methodology and performed the experiments and the measurements. M.C. and J.R. assisted with measurements. O.M., J.R. and Z.M. contributed to the analysis and interpretation of the data. J.R. and O.M. contributed to data collection and to the writing of the manuscript.

Funding: This research received no external funding.

Conflicts of Interest: The authors declare no conflict of interest.

\section{References}

1. Thomas, J.; Thomas, C.J.; Radcliffe, J.; Itsiopoulos, C. Omega-3 Fatty Acids in Early Prevention of Inflammatory Neurodegenerative Disease: A Focus on Alzheimer's Disease. BioMed Res. Int. 2015, 1-13. [CrossRef] [PubMed]

2. Kmiecik, D.; Korczak, J.; Rudzińska, M.; Kobus-Cisowska, J.; Gramza-Michałowska, A.; Heś, M. b-Sitosterol and campesterol stabilisation by natural and synthetic antioxidants during heating. Food Chem. 2011, 128, 937-942. [CrossRef]

3. Aladedunye, F.; Przybylski, R.; Matthaus, B. Performance of antioxidative compounds under frying conditions: A review. Crit. Rev. Food Sci. Nutr. 2017, 57, 1539-1561. [CrossRef] [PubMed]

4. Banerjee, I.A.; Fath, K.R.; Frayne, S.H.; Hugo, M.M.; Cohen, B. Development of self-assembled phytosterol based nanoassemblies as vehicles for enhanced uptake of doxorubicin to HeLa cells. Mater. Sci. Eng. C 2019, 97, 451-460. [CrossRef] [PubMed] 
5. Khalid, N.; Khan, R.S.; Hussain, M.I.; Farooq, M.; Ahmad, A.; Ahmed, I. A comprehensive characterisation of safflower oil for its potential applications as a bioactive food ingredient-A review. Trends Food Sci. Technol. 2017, 66, 176-186. [CrossRef]

6. Ben Moumen, A.; Mansouri, F.; Richard, G.; Abid, M.; Fauconnier, M.L.; Sindic, M.; Nabloussi, A.; Elamrani, A.; Serghini Caid, H. Biochemical characterisation of the seed oils of four safflower (Carthamus tinctorius) varieties grown in north-eastern of Morocco. Int. J. Food Sci. Technol. 2015, 50, 804-810. [CrossRef]

7. Yeilaghi, H.; Arzani, A.; Ghaderian, M.; Fotovat, R.; Feizi, M.; Pourdad, S.S. Effect of salinity on seed oil content and fatty acid composition of safflower (Carthamus tinctorius L.) genotypes. Food Chem. 2012, 130, 618-625. [CrossRef]

8. Arslan, Y. Agro-morphological characterization of wild safflower (Carthamus L., Asteraceae) species in Turkey. Pak. J. Bot. 2018, 50, 685-692.

9. Sriti, J.; Aidi Wannes, W.; Talou, T.; Mhamdi, B.; Hamdaoui, G.; Marzouk, B. Lipid, fatty acid and tocol distribution of coriander fruit's different parts. Ind. Crop. Prod. 2010, 31, 294-300. [CrossRef]

10. Roche, J.; Alignan, M.; Bouniols, A.; Cerny, M.; Vear, F.; Mouloungui, Z.; Merah, O. Sterol content in sunflower seeds (Helianthus annuus L.) as affected by genotypes and environmental conditions. Food Chem. 2010, 121, 990-995. [CrossRef]

11. Pepó, P.; Novák, A. Correlation between photosynthetic traits and yield in sunflower. Plant Soil Environ. 2016, 62, 335-340. [CrossRef]

12. Omidi, A.H.; Khazaei, H.; Monneveux, P.; Stoddard, F. Effect of cultivar and water regime on yield and yield components in safflower (Carthamus tinctorius L.). Turk. J. Field Crop. 2012, 17, 10-15.

13. Sharifi, R.S.; Namvar, A.; Sharifi, R.S. Grain filling and fatty acid composition of safflower fertilized with integrated nitrogen fertilizer and biofertilizers. Pesq. Agropec. Bras. 2017, 52, 236-243. [CrossRef]

14. Mirshekari, M.; Majnounhosseini, N.; Amiri, R.; Moslehi, A.; Zandvakili, O.R. Effects of sowing date and irrigation treatment on safflower seed quality. J. Agric. Sci. Technol. 2013, 15, 505-515.

15. Orsavova, J.; Misurcova, L.; Ambrozova, J.V.; Vicha, R.; Mlcek, J. Fatty acids composition of vegetable oils and its contribution to dietary energy intake and dependence of cardiovascular mortality on dietary intake of fatty acids. Int. J. Mol. Sci. 2015, 16, 12871-12890. [CrossRef] [PubMed]

16. Han, X.; Cheng, L.; Zhang, R.; Bi, J. Extraction of safflower seed oil by supercritical CO 2. J. Food Eng. 2009, 92, 370-376. [CrossRef]

17. Norris, L.E.; Collene, A.L.; Asp, M.L.; Hsu, J.C.; Liu, L.F.; Richardson, J.R.; Li, D.M.; Bell, D.; Osei, K.; Jackson, R.D.; et al. Comparison of dietary conjugated linoleic acid with safflower oil on body composition in obese postmenopausal women with type 2 diabetes mellitus. Am. J. Clin. Nutr. 2009, 90, 468-476. [CrossRef] [PubMed]

18. Asgarpanah, J.; Kazemivash, N. Phytochemistry, pharmacology and medicinal properties of Carthamus tinctorius L. Chin. J. Integr. Med. 2013, 19, 153-159. [CrossRef]

19. Zhou, X.; Tang, L.; Xu, Y.; Zhou, G.; Wang, Z. Towards a better understanding of medicinal uses of Carthamus tinctorius L. in traditional Chinese medicine: A phytochemical and pharmacological review. J. Ethnopharmacol. 2014, 151, 27-43. [CrossRef]

20. Oz, M. Relationship between Sowing Time, Variety, and Quality in Safflower. J. Chem. 2016. [CrossRef]

21. Mihaela, P.; Josef, R.; Monica, N.; Rudolf, Z. Perspectives of safflower oil as biodiesel source for South Eastern Europe (comparative study: Safflower, soybean and rapeseed). Fuel 2013, 111, 114-119. [CrossRef]

22. Al Surmi, N.; El Dengawi, R.; Khalefa, A.; Yahia, N. Characteristics and oxidative stability of some safflower (Carthamus Tinctorius L.). J. Nutr. Food Sci. 2015, 14. [CrossRef]

23. Roche, J.; Bouniols, A.; Cerny, M.; Mouloungui, Z.; Merah, O. Fatty acid and phytosterol accumulation during seed ripening in three oilseed species. Int. J. Food Sci. Technol. 2016, 51, 1820-1826. [CrossRef]

24. Bortolheiro, F.P.A.P.; Silva, M.A. Physiological response and productivity of safflower lines under water deficit and rehydration. An. Acad. Bras. Ciênc. 2017, 89, 3051-3066. [CrossRef] [PubMed]

25. Gouzy, A.; Massol, A.P.; Mouloungui, Z.; Merah, O. Effects of technical management on fatty acid composition of high oleic and linoleic cultivars of sunflower. Oilseeds Fats Crop. Lipids (OCL) 2016, 23, 1-5. [CrossRef]

26. Belo, R.G.; Velasco, L.; Nolasco, S.M.; Izquierdo, N.G. Dynamics of phytosterols content and concentration in sunflower grains. Crop Pasture Sci. 2018, 69, 724-732. [CrossRef] 
27. Roche, J.; Alignan, M.; Bouniols, A.; Cerny, M.; Mouloungui, Z.; Merah, O. Sterol concentration and distribution in sunflower seeds (Helianthus annuus L.) during seed development. Food Chem. 2010, 119, 1451-1456. [CrossRef]

28. Uitterhaegen, E.; Sampaio, K.A.; De Greyt, W.; Cerny, M.; Evon, P.; Merah, O.; Talou, T.; Stevens, C. Characterization of French Coriander Oil as Source of Petroselinic Acid. Molecules 2016, 21, 1202. [CrossRef] [PubMed]

29. Nestola, M.; Schmidt, T.C. Fully automated determination of the sterol composition and total content in edible oils and fats by online liquid chromatography-gas chromatography-flame ionization detection. $J$. Chromat. A 2016, 1463, 136-143. [CrossRef]

30. Hamrouni-Sellami, I.; Salah, H.B.; Kchouk, M.E.; Marzouk, B. Variations in phytosterol composition during the ripening of Tunisian safflower (Carthamus tinctorius L.) seeds. Pak. J. Biol. Sci. 2007, 10, 3829-3834.

31. Fernández-Cuesta, A.; Velasco, L.; Ruiz-Méndez, M.V. Novel safflower oil with high c-tocopherol content has a high oxidative stability. Eur. J. Lipid Sci. Technol. 2014, 116, 832-836. [CrossRef]

32. Vosoughkia, M.; Ghavamib, M.; Gharachorloo, M.; Sharrifmoghaddasi, M.; Omidi, A.H. Lipid composition and oxidative stability of oils in safflower (Carthamus tinctorius L.) seed varieties grown in Iran. Adv. Environ. Biol. 2011, 5, 897-903.

33. Merah, O.; Langlade, N.; Alignan, M.; Roche, J.; Pouilly, N.; Lippi, Y.; Bouniols, A.; Vear, F.; Cerny, M.; Mouloungui, Z.; et al. Genetic control of phytosterol content in sunflower seeds. Theor. Appl. Genet. 2012, 125, 1589-1601. [CrossRef] [PubMed]

34. Lindsey, K.; Pullen, M.L.; Topping, J.F. Importance of plant sterols in pattern formation and hormone signalling. Trends Plant Sci. 2003, 8, 1360-1385. [CrossRef]

35. Amar, S.; Ecke, W.; Becker, H.C.; Möllers, C. QTL for phytosterol and sinapate ester content in Brassica napus L. collocate with the two erucic acid genes. Theor. Appl. Genet. 2008, 116, 1051-1061. [CrossRef] [PubMed]

36. Teh, L.; Möllers, C. Genetic variation and inheritance of phytosterol and oil content in a doubled haploid population derived from the winter oilseed rape Sansibar $\times$ Oase cross. Theor. Appl. Genet. 2016, 129, 181-199. [CrossRef]

(C) 2019 by the authors. Licensee MDPI, Basel, Switzerland. This article is an open access article distributed under the terms and conditions of the Creative Commons Attribution (CC BY) license (http://creativecommons.org/licenses/by/4.0/). 